\title{
Buckling Analysis of Submarine Pressure Hulls made of Composite Materials
}

\author{
Pothamsetty Kasi V Rao ${ }^{1}$, G. Rama Prudhvi Varma ${ }^{2}$, K. Sri Vivek ${ }^{3}$, B. Jagadeesh ${ }^{4}$ \\ ${ }^{1}$ Associate Professor, Department of Mechanical Engineering, Koneru Lakshmaiah Education Foundation, \\ Vaddeswaram, A.P., India, kasi_me@kluniversity.in \\ ${ }^{2}$ Student, Department of Mechanical Engineering, Koneru Lakshmaiah Education Foundation, Vaddeswaram, \\ A.P., India, prudhvivarma123@ gmail.com \\ ${ }^{3}$ Student, Department of Mechanical Engineering, Koneru Lakshmaiah Education Foundation, Vaddeswaram, \\ A.P., India, ssrivivek@gmail.com \\ ${ }^{4}$ Student, Department of Mechanical Engineering, Koneru Lakshmaiah Education Foundation, Vaddeswaram, \\ A.P., India, jagadeesh.bandi.234@gmail.com
}

\begin{abstract}
The present work focuses on investigation of critical buckling pressure on Marine Pressure hulls subjected to hydrostatic pressure. ANSYS software is used to perform the buckling analysis. The main purpose of using composite materials in place of metals for pressure hulls is to reduce the weight of the hull without compromising on the strength. The results obtained reveal that the usage of composite materials is the best choice to replace the metals. In our present study the composites selected are high modulus (URN300) and high strength (USN150) carbon composite materials.
\end{abstract}

Keywords: Buckling analysis, submarine pressure hull, ANSYS, composite material, URN300, USN150.

\section{INTRODUCTION}

Submarines are propelled crafts built and constructed for a given period of time to conduct underwater operations. The configuration of the submarine consists of a single or double hull structure that houses all the systems and manpower needed to complete its mission. It is, however, a basic definition of a complex engineering product used for a wide variety of purposes, such as underwater exploration, underwater rescue and submarine warfare. The last one being is most widely used.

Most submarine designs have two hulls. The pressure hull is the hull that houses all the accommodation rooms, guns, weapons control systems, communications and control room, battery banks, main and auxiliary machinery. It is called a pressure hull since the hull is designed to withstand the hydrostatic pressure at the full operating depth of the submarine.

Within the outer hull, which is not pressure tight, the pressure hull is located. Because the space between the outer hull and the inner hull always remains flooded by sea water in submerged conditions. The hydrostatic pressure, which works on the outer hull, is therefore negligible.

The pressure hull in the submarine is modeled in this study using two composite materials. This study seeks to provide the best composite material from those two composites based on the numerical results of the non-linear static analysis with different hydrostatic pressure conditions considering various operating depths. The plates used in the design are carbon fiber epoxy composite (URN-300) and carbon epoxy composite (USN-150). In our work we considered cylindrical shaped pressure hull.

\section{LITERATURE REVIEW}

\subsection{Pressure hull}

In general, weight of any submarine depends on the maximum sea level depth at which the submarine is diving. Greater diving depth level requires a larger pressure hull that is capable of bearing high pressure. The level of depth used as a design consideration includes the level of operational or natural depth, the maximum permissible level of depth, and the level of collapse depth. The maximum permissible depth level is the maximum level of depth where it is possible for a submarine to operate. This depth is only reached in such circumstances. Collapse depth is the depth where the structure of the pressure hull has failed.

The pressure hull of the submarine is designed not only to withstand hydrostatic pressure, but to withstand a heavy blast shock as well. Collapse depth is, in general, a multiplier between the protection factor and the depth of service. Carlberg (2011) found that the safety factor value ranged from 1.5-2.0 for a submarine. In engineering, this figure may be appropriate. Consideration of hydrostatic load at the operating depth level and the load induced by a blast shock should be provided in a military submarine design. The effects of the blast shock will cause the structure to experience large 
deformations in a state of war, which can lead to material failure [1]. The large size and the distance of the explosion give the underwater explosion a shock effect. High wave strength can also cause damage to the pressure hull of the submarine, and some of its equipment gradually does not work properly (Friedman, 1984) [2].

Static, Dynamic and Fatigue analysis has been reported on pressure vessels by using various stiffeners inside the pressure vessels that showed as improvement in strength of pressure vessels. Also, finite element analysis on laminated hybrid the use of composite pressures vessels has been documented as being composites in pressure vessels [3-5]. Biaxial gain assessment on flawed cylindrical pressure vessels are observed to be quite important in designing the pressure vessels [6]. Effect of Thermal Environment on buckling of thick cylinder subjected to combined axial and compressive and external pressure loads [7]. Analysis of buckling strength in the case of axial load of various composite cylinder shells was observed [8]. The metal matric composites especially Aluminium reinforced with carbon nanotubes are the one of the best replacements for alloys or metals as they exhibit extra ordinary properties that will increase the buckling load of pressure hulls [9-12].

\subsection{Buckling analysis}

Buckling is an instability that contributes to the mode of failure (Assakkaf, 2003) [13]. Buckling stress may refer to a phase in which it is not possible for a structure to preserve its original shape. This occurs because the structure receives an excess of stress that results in the structure being reshaped by deflection. Buckling will restore its original form to a stable structure. In the meantime, the structure is assumed to be failing if the structure is not able to return to its original form. Factors that influence the buckling are material elasticity, size measurements, loading, and measurement factor.

\subsection{Properties of the selected composite materials}

The selection of appropriate material for pressure hull plays the important role in the design of pressure hulls. The composites used for the present study is as follows.

1. carbon fiber epoxy composite (URN-300)

2. carbon epoxy composite (USN-150)

The typical properties of the selected composites are shown in the figure 1 [14].

\begin{tabular}{lll} 
Properties & URN300 & USN150 \\
\hline Longitudinal modulus $\left(E_{1}, \mathrm{GPa}\right)$ & 380 & 131 \\
Transverse modulus $\left(E_{2}, \mathrm{GPa}\right)$ & 5.1 & 10.8 \\
Shear modulus $\left(G_{12}, \mathrm{GPa}\right)$ & 5.5 & 5.65 \\
Longitudinal strength $\left(X^{t}, \mathrm{MPa}\right)$ & 1000 & 2000 \\
Transverse strength $\left(Y^{t}, \mathrm{MPa}\right)$ & 65 & 61 \\
Shear strength $(S, \mathrm{MPa})$ & 65 & 70 \\
Poisson's ratio $\left(v_{12}\right)$ & 0.30 & 0.28 \\
Density $\left(\rho, \mathrm{kg} / \mathrm{m}^{3}\right)$ & 1750 & 1540 \\
Thickness $(t, \mathrm{~mm})$ & 0.26 & 0.15 \\
\hline
\end{tabular}

Figure 1. Material properties of URN300, USN150 [14]

\section{METHODOLOGY}

\subsection{Calculation of pressure}

The present research uses a physics approach to calculate the amount of pressure applied on the model structure, with a maximum load of:

$\mathrm{P}_{\mathrm{h}}=\mathrm{P} \times \mathrm{g} \times \mathrm{h}$

Where, $\mathrm{P}_{\mathrm{h}}=$ Hydrostatic Pressure $\left(\mathrm{N} / \mathrm{m}^{2}\right)$

$\mathrm{P}=$ Density $\left(\mathrm{kg} / \mathrm{m}^{3}\right)($ seawater $)=1025 \mathrm{~kg} / \mathrm{m}^{3}$

$\mathrm{g}=$ Acceleration due to Gravity $=9.8 \mathrm{~m} / \mathrm{s}^{2}$

$\mathrm{h}=$ Depth from surface $(\mathrm{m})$

Therefore, the maximum load acknowledged by the structure is $\mathrm{P}_{\mathrm{h}}$. Later, since its value is limited and not influential, the amount of pressure from within (submarine's cargo space) is ignored.

\subsection{Geometrical Model}

In creating geometry, SOLSH90 element was selected and a hollow cylinder is created with dimensions 21 meters outer radius and 20.5 meters inner radius i.e., the thickness of the material is $0.5 \mathrm{~m}$ and the depth of the material is 80 meters. The generated geometrical model using ANSYS software is shown in the Figure 2 and the meshed finite element model using ANSYS software is shown in the Figure 3.

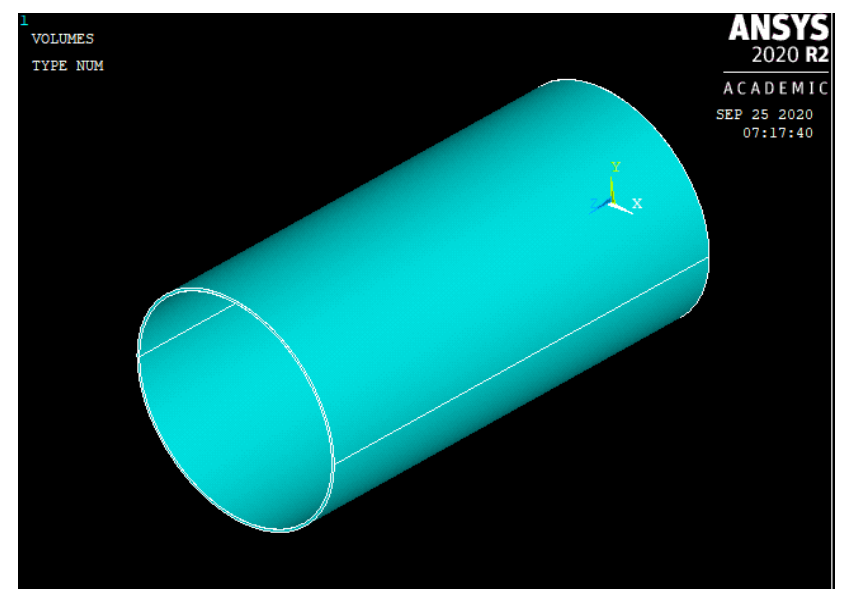

Figure 2. Geometrical model of the pressure hull

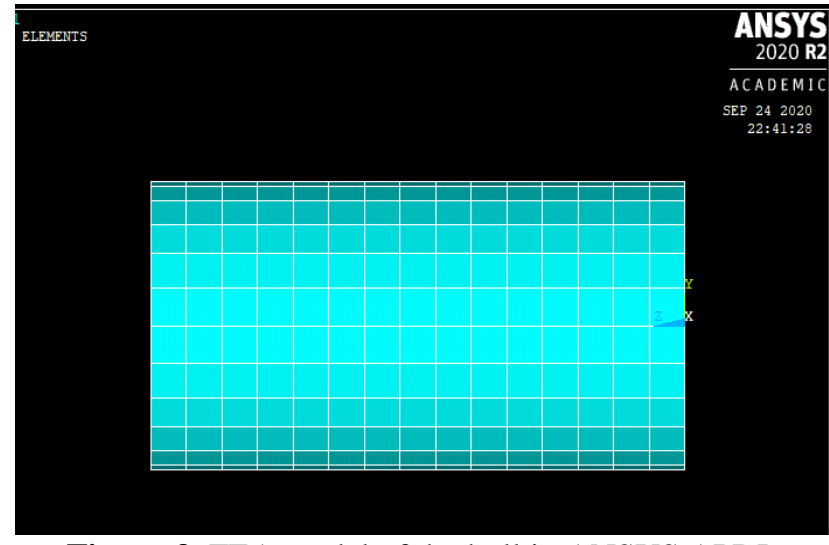

Figure 3. FEA model of the hull in ANSYS APDL

\subsection{Boundary Conditions}


Boundary condition in the FEM software analysis process is a stage in which the limits (parts to be clamped) of the model are maintained prior to loading and analysis. The clamped components are the base and don't switch, shift or rotate. Two types of boundary condition occur in the pressure hull simulation of a submarine. The first condition is the pressure hull structure, which is at one end of the model, with just one clamping point. The second condition is when both ends of the pressure hull are clamped. In this research, we use the second condition, because during analysis, the first condition does not satisfy the assumption. This is because the end point is left free to move, transfer, or rotate, so the pressure exerted by the fixed end component shifts.

\subsection{Loading Conditions}

In the analysis of the characteristics of buckling in the pressure hull, the state or depth required in this study is obtained based on the diving depth considered. The hydrostatic pressure is measured and applied to the surface using normal formulas. As shown in the Figure-4, the applied pressure is classified as the surface load.

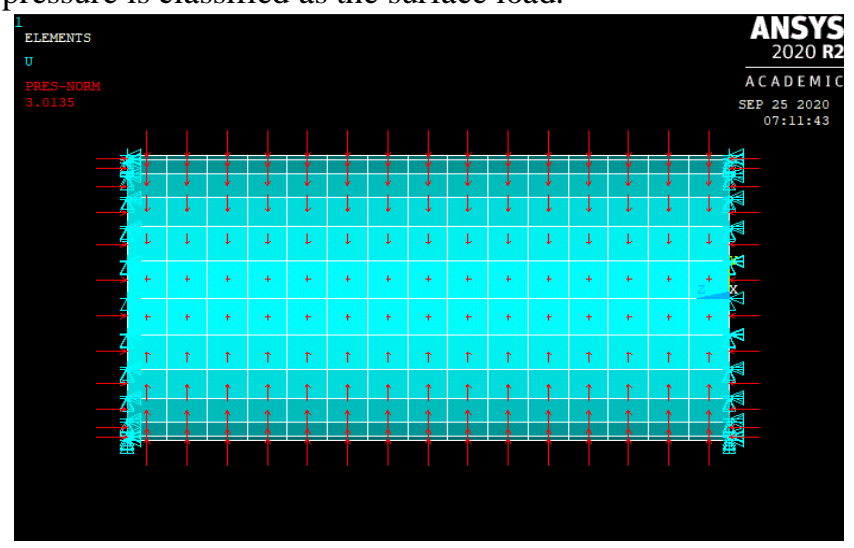

Figure 4. Boundary conditions and surface load of the pressure hull

\subsubsection{Loading at $100 \mathrm{~m}$}

In accordance with the conditions of its depth, the load acting on structure of the pressure hull of the submarine is the pressure of seawater. The plate element element will be suppressed by the pressure given.

By using hydrostatic pressure equation (h: depth surface = $100 \mathrm{~m}$ ), the hydrostatic pressure on the pressure hull of the submarine is:

$$
\begin{aligned}
\mathrm{P}_{\mathrm{h}} & =1025 \times 9.8 \times 100 \\
& =1004500 \mathrm{~N} / \mathrm{m}^{2} \text { (Pascal) } \\
& =1.0045 \mathrm{MPa}
\end{aligned}
$$

So, the load obtained by the pressure hull structure of the submarine is $1.0045 \mathrm{MPa}$

\subsubsection{Loading at $300 \mathrm{~m}$}

By using hydrostatic pressure equation (h: depth surface = $300 \mathrm{~m}$ ), the hydrostatic pressure on the pressure hull of the submarine is:

$$
\begin{aligned}
\mathrm{P}_{\mathrm{h}} & =1025 \times 9.8 \times 300 \\
& =3013500 \mathrm{~N} / \mathrm{m}^{2} \text { (Pascal) } \\
& =3.0135 \mathrm{MPa}
\end{aligned}
$$

So, the load obtained by the pressure hull structure of the submarine is $3.0135 \mathrm{MPa}$.

\subsubsection{Loading at $500 \mathrm{~m}$}

By using hydrostatic pressure equation (h: depth surface $=$ $500 \mathrm{~m}$ ), the hydrostatic pressure on the pressure hull of the submarine is:

$$
\begin{aligned}
\mathrm{P}_{\mathrm{h}} & =1025 \times 9.8 \times 500 \\
& =5022500 \mathrm{~N} / \mathrm{m}^{2} \text { (Pascal) } \\
& =5.0225 \mathrm{MPa}
\end{aligned}
$$

So, the load obtained by the pressure hull structure of the submarine is 5.0225 $\mathrm{MPa}$.

\section{Results \& Discussions}

The buckling analysis is performed on the models and Eigen value buckling factors have been identified at different modes. This was repeated at different depth of the sea water and the comparison of the buckling pressure obtained for the composite materials selected for the study (i.e. URN300, USN150) has been reported in the table 1.

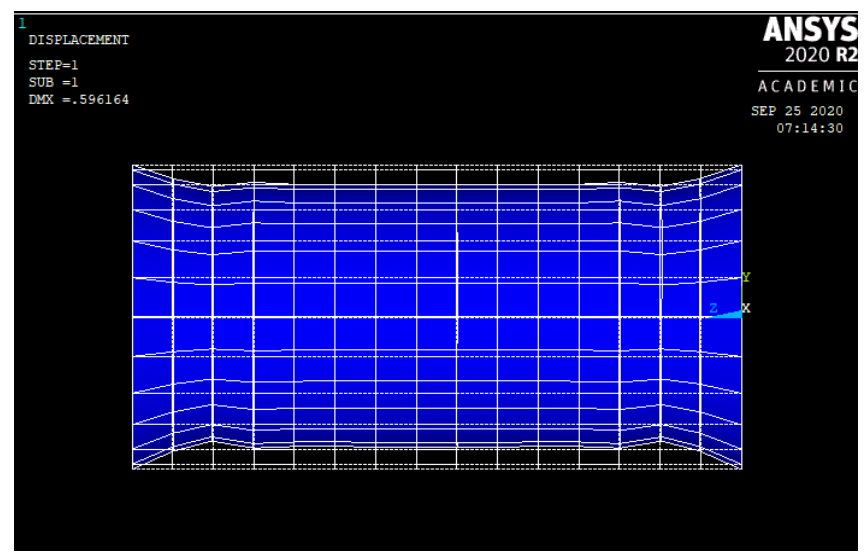

Figure 5. Buckling shape of URN-300 composite

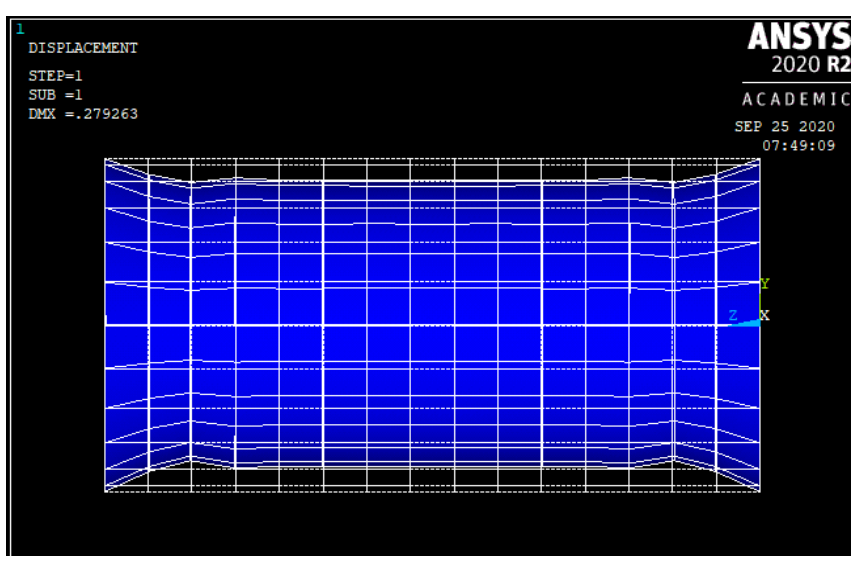

Figure 6. Buckling shape of USN-150 composite 
Table 1. The values of buckling pressure for the two composite materials

\begin{tabular}{|c|c|c|c|}
\hline \multirow{2}{*}{ Depth (m) } & Mode & URN-300 & USN-150 \\
\hline \multirow{3}{*}{100} & 1 & 2.8924 & 2.1676 \\
\cline { 2 - 4 } & 2 & 2.8959 & 2.6610 \\
\cline { 2 - 4 } & 3 & 3.3751 & 3.0411 \\
\hline \multirow{3}{*}{300} & 1 & 3.0358 & 2.8529 \\
\cline { 2 - 4 } & 2 & 3.0809 & 2.8841 \\
\cline { 2 - 4 } & 3 & 3.1477 & 3.1973 \\
\hline \multirow{3}{*}{500} & 1 & 2.9873 & 2.8841 \\
\cline { 2 - 4 } & 2 & 3.1341 & 3.0149 \\
\cline { 2 - 4 } & 3 & 3.1575 & 3.0958 \\
\hline
\end{tabular}

\section{CONCLUSION}

The composites are found to be the alternative to the metals in manufacturing pressure hulls, where the weight of the hull is reduced without compromising the strength properties. Thus the study on selected composite materials revealed that the URN300 is the best carbon epoxy composite with the high buckling pressure when compared to USN150.

\section{REFERENCES}

1. Carlberg H. 2011. Concept Design of a Commercial Submarine. Trondheim: NTNU.

2. Friedman N. 1984. Submarine design and development. London: Conway Maritime.

3. Eswara Kumar A., Sanjay Krishna G.R., Krishna Santosh R., Nagaraju M. (2017),'Fatigue analysis of pressure vessels using various stiffeners', International Journal of Civil Engineering and Technology,8(4),PP.1296-1304.

4. Eswara Kumar A., Krishna Santosh R., Ravi Teja S., Abishek E.(2018), 'Static and Dynamic Analysis of Pressure Vessels with Various Stiffeners', Materials Today: Proceedings ,5(2), PP. 5039-5048

5. Eswara Kumar A., Sanjay Krishna G.R., Shahid Afridi P., Nagaraju M. (2017),'Finite element analysis of laminated hybrid composite pressure vessels', International Journal of Civil Engineering and Technology,8(4),PP.916-934.

6. Vivek G., Imran M., Naveen P., Vineeth A.V., Rao B.N.(2018), 'Biaxial gain assessment on flawed cylindrical pressure vessels', International Journal of Mechanical and Production Engineering Research and Development ,2018, PP. 233-242

7. Eswara Kumar A., Navuri K., Manideep K., Priyanka M.(2018), 'Effect of Thermal Environment on Buckling of Thick Cylinder Subjected to Combined Axial Compressive and External Pressure loads', Materials Today: Proceedings ,5(2), PP. 3298-3305

8. Radhakrishna K., Rao S.S. (2019), 'Analysis of buckling strength in the case of axial load of various composite cylinder shells', International Journal of Recent Technology and Engineering, 7(6), PP.769-771.

9. Rao P.K.V., Raghu Kumar B. (2019), 'Influence of size and weight fraction of carbon nanotube on coefficient of thermal expansion of Al-CNT metal matrix', Journal of Mechanical Engineering Research and Developments, 42(1), PP.85-89.

10. Rao P.K.V., Raghukumar B., Sudheer Kumar B., Phanindra Swamy G., Ganga Raju Y., Khan
P.S.A.(2018), 'Investigation of flexural and impact strength of carbon nanotube reinforced AA7075 metal matrix', International Journal of Engineering and Technology(UAE) ,7(2), PP. 764-767

11. Rao P.K.V., RaghuKumar B., Veera Sai Chandh Y., Teja A. (2019), 'Finite element analysis of CNT reinforced aluminium composite subjected to mechanical loading', Materials Today: Proceedings, 16, PP.308-313.

12. Rao P.K.V., Raghu Kumar B., Saiteja A., Srikar N.S.V., Sreenivasulu V., Adithya Prakash D.(2018), 'Experimental investigation of thermal stability of carbon nanotubes reinforced aluminium matrix using TGA-DSC analysis', International Journal of Mechanical and Production Engineering Research and Development ,8(3), PP. 161-168.

13. Assakkaf I. A. 2003. Columns: Buckling (Pinned Ends) (Doctoral dissertation, University of Maryland, College Park).

14. Lee, DG \& Lee, Cheol-Hee \& Lee, Hak \& Hwang, Hui \& Kim, JW. (2004). Novel applications of composite structures to robots, machine tools and automobiles.17-39.10.1016/j.ccmpstruct.2004.04.044. 